\title{
Cast, cut, sample and analyze: A practical approach to processing speleothems for paleoclimate reconstruction
}

\author{
Ali Pourmand \\ Miami, USA, 12-14 May 2014
}

\begin{abstract}
Speleothems (cave deposits) have emerged as one of the richest archives mined for paleoenvironmental reconstructions (Fairchild and Baker 2012). However, due to their fragile structure and often complex history, cave deposits must be handled with great care for accurate reconstruction of climate variability during Pleistocene and Holocene epochs. In May 2014, the Neptune, Paleoclimate and Stable Isotope Labs at the Rosenstiel School of Marine and Atmospheric Science at the University of Miami, extended the opportunity to 22 enthusiastic participants from seven countries to attend a three-day workshop on processing speleothems.
\end{abstract}

Each day began with short lectures on the analytical methodologies relevant to the activities of the day. Stalagmites were embedded in epoxy, then sectioned with circular and band saws and hand-polished. Following this, $\mathrm{X}$-ray fluorescence scanning was discussed for high-resolution and non-destructive elemental analysis. We also discussed different sampling techniques using manual drills and an automated micro-mill that can be used to sample for trace element, stable isotope and U-Th analyses. We also focused on how to measure Sr/Ca and $\mathrm{Mg} / \mathrm{Ca}$ ratios and trace elements by employing inductively-coupled plasma optical emission spectroscopy (ICP-OES). And lastly, direct-dilution and standard calibration techniques were introduced. The methodologies explored are described below in more detail.

\section{Improving cave hydroclimate} reconstruction

The oxygen isotope composition of stalagmites is often interpreted as a proxy for changes in rainfall amount. Cave hydroclimate reconstruction, however, can be significantly improved if the oxygen isotopic composition of the water from which speleothems precipitate is known. One such novel analytical technique for hydrogen and oxygen isotopic analyses $\left(\delta^{2} \mathrm{H}\right.$ and $\delta^{18} \mathrm{O}$ values) of fluid inclusions in speleothems is cavity ring-down spectroscopy (Arienzo et al. 2013). This technique is comparable to traditional methods of dual-inlet isotope ratio mass spectrometry (IRMS) or continuous-flow (CF)-IRMS, and has been used successfully to measure the isotopic composition of fluid inclusions in stalagmites from submerged caves in the Bahamas.

\section{Clumped isotopes in speleothem analysis} A new field of rapid growth is the clumping of isotopes in paleothermometry (Ghosh et al. 2006). Isotopologues (molecules with

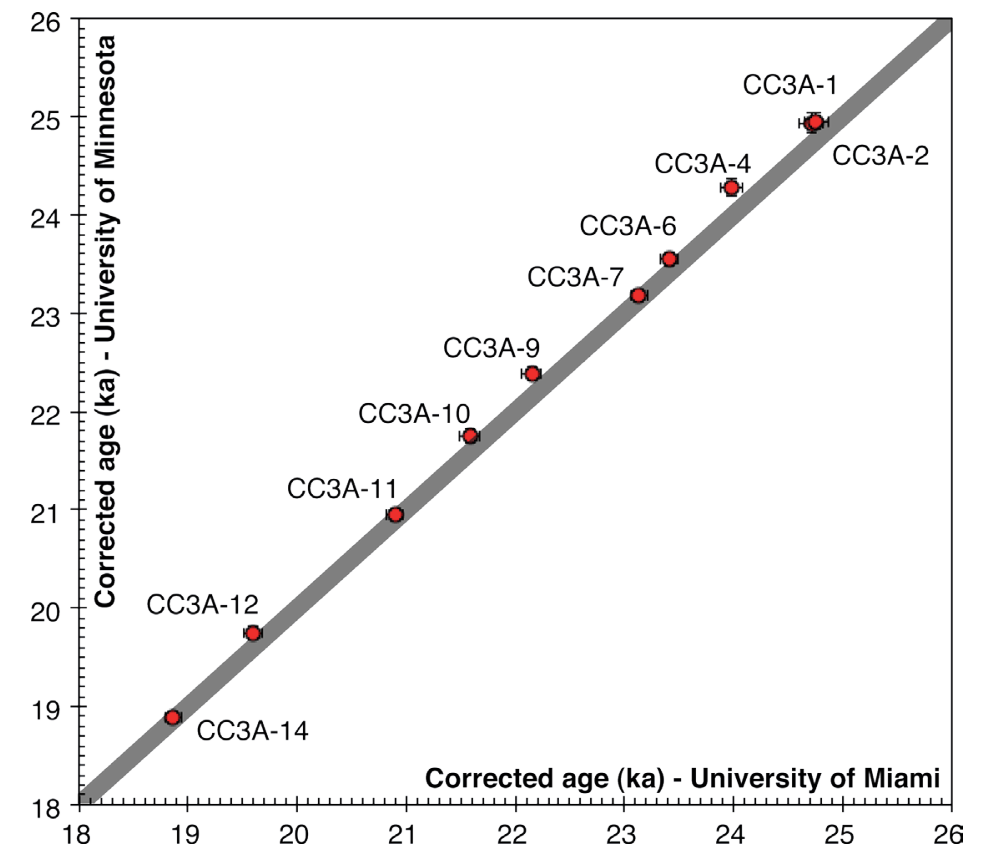

Figure 1: Comparison between U-Th ages determined at the University of Minnesota and the University of Miami on a speleothem from Cathedral Cave, Utah (Modified from Pourmand et al. 2014).

similar chemical but different isotopic composition) have been successfully measured in various carbonate deposits for paleo-temperature reconstructions. Speleothems, however, have thus far proven elusive. Limited available data have shown that cave temperatures reconstructed using clumped isotopes are in excess of expected or monitored temperatures (Daëron et al. 2011). During the workshop, we saw the extraction and purification line for $\mathrm{CO}_{2}$ and how measurements of clumped isotopes are made on the mass spectrometer. New temperature reconstructions based on modern cave deposit experiments confirm previous findings on the complexity of interpreting clumped isotope reconstructions in speleothems.

\section{Multi-collection ICP-MS: a novel technique} We also discussed a novel analytical technique for U-Th geochronometry: multi-collection ICP-MS. We saw the procedure for sample dissolution, ${ }^{229} \mathrm{Th}^{2}{ }^{233} \mathrm{U}-{ }^{236} \mathrm{U}$ spike addition, $U$ and Th purification, and isotope dilution mass spectrometry. Data reduction is performed through an open source algorithm that uses Monte Carlo simulation for propagation of random and systematic uncertainties (Pourmand et al. 2014). A significant advantage of this approach is consideration of $U$ and Th isotope covariances and propagation of decay constants on corrected ages. The agreement between ages measured in two laboratories demonstrates the fidelity of this technique (Fig. 1). The workshop was concluded with presentations by several participants on modern cave monitoring and paleoreconstructions.

\section{AFFILIATIONS}

Department of Marine Geosciences, Rosenstiel School of Marine and Atmospheric Science, The University of Miami, USA

\section{CONTACT}

Ali Pourmand: apourmand@rsmas.miami.edu

\section{REFERENCES}

Fairchild IJ, Baker A (2012) Speleothem Science. John Wiley \& Sons, 416 pp

Pourmand A et al. (2014) Geostand Geoanal Res 38 : 129-148

Arienzo MM et al. (2013) Rapid commun mass spectrom 27: 2616-2624

Ghosh P et al. (2006) Geochim Cosmochim Acta 70: 1439-1456

Daëron M et al. (2011) Geochim Cosmochim Acta 75: 3303-3317 